\title{
CONTINUUM RELIGIOSO NIPO-BRASILEIRO: O CASO DO BUDISMO CÁRMICO DA SHINGON
}

\author{
Rafael Shoji
}

Resumo: Através de pesquisas de campo realizadas entre os anos de 2000 e 2004, esse artigo mostra que a evolução do budismo Shingon no Brasil deve ser entendida como um processo sincrético com duas matrizes: a primeira nikkei, dada pelo budismo esotérico e pelo culto aos antepassados trazido pelos imigrantes japoneses, e a segunda tipicamente brasileira, dada pelo continuum de religiōes de possessão como o espiritismo e a umbanda. Os principais pontos de contato entre essas duas matrizes estão no conceito de carma e em uma religiosidade orientada para resultados, presentes tanto no campo religioso japonês como brasileiro, propiciando um sincretismo acumulativo que ajuda a preencher lacunas doutrinais. Conforme é apontado nas conclusões, a busca de resultados através do carma ajuda a explicar a presença de brasileiros em novas religiōes budistas no Brasil, sendo o ponto de partida mais comum da reinterpretação desses movimentos.

Palavras-chave: Budismo Shingon - Sincret ismo - Carma - Conversão.

Abstract: Based on a fieldwork realized between the years of 2000 and 2004, this paper discuss the evolution of Shingon buddhism in Brazil as a syncretic process with two matrices: the first nikkei, through the esoteric buddhism and ancestor cult brought by the japanese immigrants, and a second one typically brazilian, represented by a continuum of religious moviments as espiritismo and umbanda. The main points of contact between these two matrices are the concept of karma and a religiosity oriented to wordly results, elements found in the japanese and brazilian religious field. These elements support an additive sincretism that helps to fill doutrinal gaps. As summed up in the conclusions, it will be defended that the search of results through karma helps to explain the presence of brazilians in new buddhist religions, being the natural starting point of reinterpretation.

Keywords: Shingon Buddhism - Syncretism - Karma - Religious Conversion.

Doutor em Ciência da Religião pela Universidade de Hanover, pós-doutorando em Ciência da Religião pela PUC/SP (rafaelshoji@uol.com.br) 


\section{INTRODUÇÃO}

Ainda que budistas ocidentais sejam uma minoria, o budismo se populariza, recebendo outras influências nesse processo. Em Suzano, um município perto da cidade de São Paulo, todas as manhãs se forma uma fila para que se realize uma "bên çáo" com os "padres", como é chamado o ritual de consulta aos monges Shingon. A grande maioria é de mulheres e de brasileiros sem descendência japonesa. Cada devoto paga uma pequena quantia pelo que é chamado de "consulta" e "passe", en trando em uma fila de espera para ser atendido. Enquanto se espera, cada devoto escreve qual é o seu problema ou os problemas em nome de quem o participante está ali presente. A maior parte das situações que se espera resolver são problemas de saúde, desemprego ou de desarmonia familiar, mas não é raro que os fiéis vejam a causa de seus problemas na "macumba". Em duas pequenas casernas são realizados esses rituais de consulta aos monges do Shingon. Nos finais de semana existem cerimônias que são bastante populares, principalmente a missa aos antepassados e o ritual do fogo (jap. goma), mas existem cerimônias que se destinam à proteção contra roubos de carros ou de casa, rituais que têm um claro apelo social.

A partir desse material de campo, em termos teóricos esse artigo traz elementos para situar o budismo Shingon no Brasil como sendo um movimento sincrético dado pelo encontro da religiosidade japonesa com as religiōes brasileiras, sendo o princípio comum dado por uma busca de resultados práticos a partir do carma e da intercessão do mundo espiritual.

De fato, uma característica das religiōes japonesas é a busca de benefícios nesse mundo, o que tem sido defendida como uma constante em praticamente todos os movimentos religiosos japoneses. Em contraste com uma religião popular ou primal (Pye, 1996). Reader e Tanabe defendem como tese principal que a obtenção de benefícios nesse mundo (jap. genze ryaku) revela um continuum nas diferentes religiōes no Japão, que eles rotulam de religião comum, no sentido de ser uma visão de mundo ainda largamentecompartilhada pela populaçãojaponesa (Reader e Tanabe, 1998). A possibilidade de comprovação prática de uma religião significa que é pos-

Debates do NER, Porto Alegre, Ano 7, n. 9, P. 37-56, JAn./Jun. 2006 
sível obter benefícios através de práticas religiosas e da intercessão do mundo espiritual. Proteção, soluções para problemas de saúde, financeiros ou de família, são entendidos como possíveis de serem obtidos através de uma transação com o mundo espiritual. Isso não significa necessariamente uma visão primordialmente materialista, mas freqüentemente inclui também uma prática religiosa que busca criar condições para a realização do que se necessita, através de uma ética e crença na possibilidade de realização desses objetivos. ${ }^{1}$

No que se refere ao carma (jap. innen), no contexto do budismo japonês os benefícios nesse mundo estão intimamente associados com o culto aos antepassados. Como crença popular japonesa, uma morte infeliz ou violenta, ou a negligência com as obrigaçõoes em relação aos antepassados resultam em efeitos negativos na vida presente. Oferecendo ao mundo espiritual os frutos das práticas ou ritos, considera-se que exista uma retribuição desses efeitos na vida presente. Dessa forma, melhorando a situação espiritual dos antepassados, melhora-se a situação presente do praticante. O carma pode então ser transformado através de uma interação com o mundo espiritual e através do culto aos antepassados, que dessa forma mantém uma influência negativa ou positiva sobre seus descendentes.

A partir desse conceito da busca de resultados nesse mundo a partir do carma, no Shingon dos convertidos essa perspectiva japonesa se encontra com o continuum dado pelas religiões brasileiras baseadas na mediunidade e possessão (Camargo, 1973), sofrendo influências do Espiritismo e das religiōes afro-brasileiras. Esse padrão pode ser observado não só em movimentos como o Shingon, mas também em outras novas religiōes japonesas que têm sua origem no budismo esotérico japonês. De uma forma geral, para muitos movimentos budistas japoneses o carma é freqüentemente des-

\footnotetext{
${ }^{1}$ Esse é um padrão em várias novas religióes japonesas, ver por exemplo a Reyukai em Hardacre (1984). Nesse aspecto, sobre a Shinnyo-en, ver Mikiko (1995). Reader e Tanabe associam essa expectativa de benefícios nesse mundo com paz de espírito (anshin) e fé (shinkô), ver Reader e Tanabe (1998, p. 17-18).
} 
tacado como causa dos problemas, cuja solução varia para cada grupo, desde a realização de rituais até uma orientação mais laica de recitação de sutras ou mantras em casa.

\section{ASPECTOS GERAIS DO BUDISMO SHINGON}

O desenvolvimen to do budis mo tântrico, também chamado de Vajrayana, ocorreu primordialmente a partir do século VI na Índia, em uma fase posterior ao surgimento do budismo Mahayana. Como resultado de uma influência tântrica, rituais e divindades hindus foram incorporadas ao Budismo através de uma reinterpretação dos métodos e condições para se atingir a iluminação. $\mathrm{O}$ termo budismo esotérico (jap. mikkyô) tem sido o nome mais utilizado para se designar a corrente budista de influência tântrica que chegou ao Japão durante o século IX e que desde então se desenvolve também a partir das influências locais do xintoísmo e das outras correntes budistas que se estabeleceramposteriormente. $\mathrm{O}$ budismo tibetano foi o resultado do sincretismo desta corrente tântrica com a religião local tibetana (Bon). Além das diferentes influências devido às diferentes religiós e culturas locais, a corrente tibetana do budismo tântrico se distingue da japonesa por ter incorporado os escritos e a influência tântrica de um período posterior, com um maior contato com a cultura indiana, devido à proximidade geográfica. No caso do Japão, após ter se desenvolvido na dinastia Tang na China, no século VIII, o budismo esotérico foi estabelecido através de Kûkai, nome póstumo Kôbô Daishi, e Saichô, fundador da escola Tendai e também conhecido com o título Dengyô Daishi, que tinham embarcado para a China nos primeiros anos do século IX. No Japão, além do budismo esotérico estar presente no Shingon e na escola Tendai, ele também tem reaparecidoem diversos novos movimentosreligiosos, como a Agonshû e a Shinnyo-en. Kûkai estabeleceu sua escola no monte Kôya, mas depois de sua morte uma série de divisões e disputas ocorreram, fazendo com que atualmente a Koyasan seja somente um dos ramos do Shingon (Yamasaki, 1988, p. 37). 
Como um conjunto de práticas complexas e altamente ritualizadas, somente alguns aspectos do Shingon podem ser aqui indicados. Em contraste com o budismo esotérico, o Shingon é esotérico no sentido de que seus ensinamentos e práticas mais internos só devem ser transmitidos de mestre para discípulo (Yamasaki, 1988, p. 56). Ao contrário da maior parte das correntes budistas, os ensinamen tos principais - os sutras Dainichi-kyô e Kongôch ô-gyô- são baseados não no Buda histórico Shakyamuni, mas nos ensinamentos de Dainichi Nyorai, que teriam sido descobertos em uma torre de ferro pelo terceiro patriarca Nagarjuna, a primeira figura histórica na série de patriarcas cujo oitavo representante é Kûkai. A principal divindade é Dainichi Nyorai, entendido freqüentemente como a energia essencial da vida, sendo o universo e as outras divindades uma manifestação dessa energia (Yamasaki, 1988, p. 64). O conjunto de práticas do Shingon está bastante associado ao que é descrito nos dois sutras principais. As principais práticas, especialmente as contemplativas, buscam uma purificação das atividades do corpo, fala e mente.

Os instrumentos para essa purificação são geralmente práticas baseadas em mudras, mantras e mandalas, em um processo que é freqüentemente descrito como kaji, uma prática que conduz a graça ou mérito através da interação entre o praticante e a divindade escolhida (Yamasaki, 1988, p. 106). Tradicionalmente os adeptos têm uma divindade guardiã, conhecida no ritual de iniciação, podendo ser realizadas diversas atividades contemplativas e de visualização, muitas vezes associados a mandalas e a elementos da natureza. ${ }^{2} \mathrm{O}$ ritual é um elemento muito importante no Shingon, existindo diversas atividades para divindades específicas, muitos com finalidades práticas associadas.

Nos aspectos mais populares e devocionais, o termo kaji é também freqüentemente utilizado em rituais objetivando propósitos próprios, atra-

\footnotetext{
2 Para uma descrição geral das práticas do Shingon, além de Yamasaki (1988), consultar Goepper (1983). Para uma descrição mais detalhada desse aspecto no caso das mandalas, bem como para uma discussão de posteriores influências chinesas na sua elaboração, consultar Ten Grotenhuis (1999, p. 33-950).
} 
vés da energia da interação com as divindades. ${ }^{3}$ Nesse contexto, um dos rituais públicos mais populares é o goma, a cerimônia do fogo, realizado tradicionalmente para o bodisatva Fudô Myô-ô, no qual desejos inscritos em tabuletas de madeira são queimados ritualmente. Em termos históricos, esse ritual é aparentemente originário dos rituais brâmanes a Agni, no qual os pedidos são levados aos céus pela fumaça e pelas chamas. No Shingon, ele também tem esse significado mágico de realização de pedidos, apesar de seu significado central ser simbolicamente queimar a desilusão e os apegos com o fogo da sabedoria (Yamasaki, 1988, p. 74).

No contexto popular também são comuns consultas e práticas devocionais específicas buscadas pelos leigos, no qual o carma dos antepassados é um elemento doutrinal importante para problemas específicos como doenças ou a influência de espíritos negativos. O carma dos antepassados, nessas práticas, está estreitamente associado ao budismo tradicional japonês, baseado no clã tradicional (jap. ie).

Adicionalmente, é interessante destacar aspectos gerais da presença do sincretismo no budismo esotérico japonês. Desde o início da história do Shingon houve uma tendência sincrética, com a incorporação de elementos e deuses hindus até a tendência de justapor kamis do xintoísmo a bodisatvas no Shingon. Esse aspecto sincrético do Shingon foi ainda mais destacado com o desenvolvimento do movimento popular Shuguendô no Japão. Em termos doutrinais, essas incorporações puderam ser freqüentemente justificadas a partir do seguinte raciocínio: sendo tudo existente entendido como uma manifestação de Dainichi Nyorai, elementos de outras religiōes são potencialmente incorporados como manifestações especiais ou locais dessa verdade.

Outro aspecto do sincretismo que acompanha o Shingon é a incorporação de elementos mágicos diversos, desde a sua origem. Longe de serem negados, esses aspectos foram enfatizados em diversos momentos da história do Shingon, muitas vezes entendidos como uma reafirmação não só da vida

${ }^{3}$ Nesse sentido, o termo é freqüentemente usado como kaji kitô, conforme Yamasaki (1988, p. 78).

Debates do NER, Porto Alegre, Ano 7, N. 9, P. 37-56, JAn./Jun. 2006 
mundana, mas também do selfe do desejo humano (Yamasaki, 1988, p. 810,72-79).Se em termos tradicionais essas características são freqüentemente contrárias à formulação original do budismo, no caso do Shingon eles são representados em uma escola budista considerada bastante ortodoxa no Japão. De fato, em termos históricos o Shingon freqüentemente rejeitou o budismo Mahayana por estar longe dos interesses das pessoas comuns e por valorizar mais o aspecto filosófico (Yamasaki, 1988, p. 9).

Por último, outra característica histórica que facilita a incorporação de outras práticas no budismo esotérico é a tendência de separação e formação de novas escolas, que atuam de maneira semelhante mas com possíveis diferenças doutrinais e de estilo.Isso ocorre devido à característicade transmissão esotérica de mestre a discípulo. Com isso, cada mestre pode eventualmente ter a possibilidade de incorporar elementos de outras religiōes, por não ter sempre uma clara esfera de poder que defina a ortodoxia. ${ }^{4}$

\section{TEMPLOS DO BUDISMO ESOTÉRICO JAPONÊS NO BRASIL}

Em 1934 chegou ao Brasil o Rev. Shinba no navio Kawamachi-maru. Rev. Shinba iniciou as atividades do Shingon na cidade de São Paulo, inicialmente se estabelecendo de forma independente e posteriormente se estabelecendo como um templo da Koyasan Shingon. Um outro templo da

\footnotetext{
${ }^{4}$ Enquanto que uma ortodoxia dada por livros é um elemento importante para budistas mais intelectualizados, uma contraposição importante é a correlação entre sincretismo e prática esotérica no budismo nos países ocidentais. Isso já foi mostrado em estudos sobre o budismo em países de maioria budista, conforme Bechert (1978), Gombrich e Obeyesekere (1988, p. 462) e Spiro (1982, p. 162-163). No caso do Shingon no Japão, ver Yamasaki (1988, p. 37). O esoterismo no budismo, freqüentemente de origem tântrica, tem como tendência o seguimento de um mestre e um ensinamento na base de iniciações, o que gera uma potencial fragmentação do ensinamento. A possibilidade de independência dos mestres torna o budismo passível de influências individuais diversas, como a abertura e combinação com outras idéias religiosas.
} 
Koyasan, chamado Koyasan Koyaji,foi estabelecido posteriormente no bairro de Vila Antonieta, na zona leste da cidade de São Paulo, onde é atualmente a sede. Atualmente existem 6 templos na missão da Koyasan, mas existe uma percepção de extinção na maior parte dos templos, porque os imigrantes e sacerdotes estão envelhecendo e muitos descendentes não se interessam em continuar as atividades. No total, atualmente existem cerca de 9 sacerdotes na Koyasan, sendo a maioria deles imigrantes que se dedicam à carreira monástica somente depois da aposentadoria em outra profissão.

O mais ativo templo da Koyasan e com maior presença de brasileiros é o templo em Suzano, nas imediaçóes da cidade de São Paulo. Com o antigo nome de Shingonshu Daijo-ha, o templo foi incorporado à Koyasan com o nome de Igreja Shingonshu Kongoji. Seus fundadores foram os imigrantes japoneses Oda, Nishioka e Anzai, que cedeu o terreno onde hoje está construído o templo. Esse templo em Suzano, que recebe muitos freqüentadores da cidade de São Paulo, recebe diariamente cerca de 50 visitantes, a grande maioria brasileiros. Em dias de cerimônia nos finais de semana, especialmente nas cerimônias de goma, existem aproximadamente 300 pessoas, mais da metade sendo brasileiros. Apesar de existirem alguns brasileiros e descendentes em treinamento para funçóes sacerdotais, atualmente existe somente um sacerdote brasileiro, que atua em Suzano. Alguns brasileiros passaram pelo Shingon como monges, mas não permaneceram. ${ }^{5}$

$\mathrm{Na}$ cidade de Suzano existe ainda outro templo Shingon. Devido a desentendimentos no que hoje é o templo da Koyasan, foi construído outro templo em local próximo, chamado Igreja Budista Nambei Yugazam Jyomiyoji. Esse templo se denomina como pertencendo a linha Shingon associado ao Shuguendô, sendo associado ao templo Daigoji no Japão. Apresentando uma grandiosa e tradicional construção, ele é freqüentado principalmente por imigrantes e descendentes, se conservando etnicamen-

\footnotetext{
${ }^{5}$ Entre eles, os pioneiros rev. Gonçalves e rev. Murillo Azevedo, que posteriormente se converteram, respectivamente, aos ramos Higashi e Nishi da escola Jôdô Shinshû. Os motivos de afastamento foram, em ambos os casos, o sincretismo com tradiçóes africanas que eles constataram.
} 
te japonês e bastante tradicional, apesar do número de praticantes ser cada vez menor.

Além dos templos associados à Koyasan e da Igreja Budista Nambei Yugazam Jyomiyoji, constam também alguns templos independentes, que se consideram pertencentes derivados da linha do Shingon (Osaki, 1990, p. 95-96). Em termos do budismo esotérico japonês, existem ainda dois templosTendaino municípiode Diadema,que seguem um padrão sincrético semelhante ao que ocorre no Shingon. ${ }^{6}$ Além disso, têm se estabelecido em São Paulo alguns novos movimentos religiosos com influência do Shingon. ${ }^{7}$

No item a seguir descreverei com mais detalhes o templo da Koyasan em Suzano. Nele é possível constatar com mais clareza como se desenvolve a presença do sincretismo com as religiōes afro-brasileiras. Além de ser um exemplo de um budismo brasileiro em formato sincrético, ele também exemplifica elementos da perspectiva aqui adotada sobre essa faceta do sincretismo nipo-brasileiro.

\footnotetext{
${ }^{6}$ Um dos templos se chama Jogan-Ji Fudô Myô-ô e foi construído há mais de 25 anos, sendo considerado uma atração turística da região. O templo é liderado por duas sacerdotisas e associado ao templo Tyoujiu-ji Kihara Fudô-Son no Japão. Fudô Myô-ô é a divindade principal nesse templo e existe uma ênfase nas consultas, sendo ainda realizada a cerimônia de goma, na qual são queimadas as tabuletas de madeira com pedidos. $\mathrm{O}$ templo da linha Tendai em Diadema chama-se Comunidade Kannon, mas está decadente desde a morte do fundador. Até alguns anos atrás era realizada anualmente a cerimônia do andar sobre o fogo, uma das práticas esotéricas do Tendai, o que atraia uma grande atenção de populares e da imprensa. Conforme entrevistas, nas práticas cotidianas constam ainda consultas e busca de curas, ocorrendo o sincretismo da bodisatva Kannon com Maria e Iemanjá.

7 Um grupo estabelecido em São Paulo que sofre uma grande influência do Shingon, apesar de não se declarar pertencente ao budismo esotérico, é a Agonshû, que tem se adaptado rapidamente à religiosidade brasileira de busca de resultados através da melhora do carma. Outro exemplo é a Shinnyo-en, que apesar de independente tem uma forte associação com o templo Daigoji e também vem se estabelecendo em São Paulo. Diferentemente de outros movimentos religiosos japoneses, a Shinnyo-en tem um forte caráter mediúnico.
} 


\section{PRÁTICAS POPULARES}

\section{DA KOYASAN SHINGON NO BRASIL}

A maioria dos freqüentadores da Igreja Shingonshu Kongoji vem da cidade de São Paulo e os contatos são feitos oralmente, existindo inúmeros brasileiros sem descendência japonesa que freqüentam o local, a maioria deles pertencentes às classes média e baixa. A presença e busca dos descendentes japoneses se dá mais para a realização de rituais funerários. As chamadas consultas e benzimentos são um elemento bastante importante para os freqüentadores do templo, sendo realizadas em duas pequenas casernas separadasdo alojamentodos monges e do edifícioprincipal do templo. As principais motivações são problemas de saúde, financeiros ou de desentendimento familiar. A grande parte dos brasileiros não tem uma associação formal com o templo ou uma busca mais doutrinal do budismo, apesar de algunsdeles freqüientarem as consultase as cerimôniashá muitosanos. Alémdo templo Shingon, muitos devotos também freqüentamsimultaneamente outras práticas, como o catolicismo, a Seicho-no-ie e religiōes afro-brasileiras. Apesar disso, muitos se consideram budistas e nos contatos que realizei encontrei fiéis que não só se considerambudistasapesar das práticas múltiplas, mas também já freqüentam o templo assiduamente desde o início da década de 80 .

Para fins etnográficos e como dado empírico de observação participante, é importante relatar uma das consultas e benzimento típicas, que mostra a presença do sincretismo na suspensão de barreiras entre o Shingon e as tradiçóes afro-brasileiras. Cada devoto paga uma pequena quantia, retirando uma senha e entrando em uma fila de espera para ser atendido. Enquanto isso, cada participante escreve qual é o seu problema ou os problemas em nome de quem o devoto está ali presente. Na cerimônia em que me foi permitido participar, existiam 12 pessoas, das quais somente um era homem e somente uma era descendente de orientais. A maioria das mulheres eram em sua maioria donas de casa, havendo somente um homem, que estava desempregado. Os participantes pertenciam a diversas classes sociais e idades, apesar de uma predominância da classe média baixa. Todos os participantes sentavam-se em cadeiras laterais e o monge de costas para os 
participantes, de frente para um altar com uma imagem de Kôbô Daishi. Inicialmente foram lidos pelo monge os papéis escritos pelos devotos, sendo esclarecidas, a partir de conversas na frente do grupo, as dúvidas que ele viesse a ter sobre cada um dos problemas descritos. Os problemas mais freqüentes eram os de saúde, seguidos por problemas financeiros. A partir daí, ainda em grupo, o monge se dirigia a cada um dos participantes, investigando as possíveis causas e soluções para os problemas. Algumas vezes foram dados conselhos práticos, como por exemplo o tipo de advogado mais adequado para um determinado caso ou qual seria a melhor orientação para um negócio que não estava sendo rentável. Também em relação a problemas de saúde eram dados conselhos médicos, reafirmada pela especialização do monge em medicina chinesa e seus conhecimentos de homeopatia.

Em um segundo momento são realizadas as consultas realmente espirituais para cada participante, como forma de investigar a real razão dos problemas. Em geral, as causas para os problemas se dividiam em duas categorias. A primeira era devido ao carma a partir dos antepassados, o que teria uma conseqüência direta sobre os seus descendentes. Segundo o monge, por exemplo, o problema de separação enfrentado por uma das participantes era causado por um aborto realizado por um antepassado. Essa relação causal com o carma dos antepassados também foi comum no caso de doenças que os participantes queriam curar. Uma segunda causa para os problemas seria a "macumba", com o objetivo de prejudicar ou causar males a alguém. A expectativa de que a causa do mal fosse essa já fazia parte de alguns participantes. O único senhor presente, desempregado, perguntava: "nada dá certo, tá tudo trancado, não será macumba?". Essa associação é reforçada pelo vocabulário utilizado pelo monge, que além de "macumba" utiliza "espírito ruim" e "encosto", quando tenta fazer intelegível as causas dos problemas. Depois do esclarecimento das causas dos problemas individuais, pede-se que todos os participantes se concentrem e façam um mudra específico, mostrado pelo monge. É então realizada uma cerimônia de purificação, a partir da recitação de um mantra específico. Ao final cada um é novamente purificado individualmente, novamente através de um mantra, e o monge realiza mais uma consulta individual para 
verificar se existe algo mais a ser realizado, para que os problemas descritos possam ser resolvidos. Nesse momento foram repassados alguns conceitos do budismo, como a importância das reverências e o significado de mudras e de Kôbô Daishi para o Shingon. Com uma participante, na qual foi identificada uma "for te macu mba", foi realizado um ritual particular, a partir de uma sequiência de mudras e mantras específicos. Para alguns devotos nada mais precisa ser feito, outras vezes é pedido para que seja encomendado, na secretaria, um determinado número de dias de "missa", como também é chamado o ritual realizado diariamente somente pelos monges. Nessas cerimônias, devido a essas solicitações dos devotos, é também realizada a purificação do carma dos antepassados, como maneira de livrar os descendentes das conseqüências negativas desse carma.

De uma maneira geral, a impressão causada é que a maior parte dos participantes entende a cerimônia como um passe ou benzimento, muitas vezes também se referindo ao fato de "desfazer trabalhos", ignorando grande parte dos conceitos tradicionais do budismo ou de um aspecto mais intelectualizado. Devido à presença de elementos mágicos e da busca de soluçôes para problemas nesse mundo, o que mais se encontra é um budismo de resultados, centrado especialmente no carma e em elementos mais mágicos, acrescidos da sua interpretação a partir das religiōes brasileiras. A suspensão da barreira entre os sistemas religiosos, no caso desse templo da Koyasan, ocorre especialmente nesse contexto. A causa dos problemas dos freqüentadores é entendida em geral como um resultado do carma próprio ou dos antepassados ou então a causa é entendida como algum ritual de origem afro-brasileira. $\mathrm{O}$ resultado desejado, que é a eliminação do problema, é obtido através da consulta com os sacerdotes ou na realização de rituais para os antepassados.

Elementos mágicos e populares também existem nas cerimônias que ocorrem nos finais de semana do templo, mas nesse caso eles parecem estar mais associados à ortodoxia do Shingon, contando com uma presença maior de imigrantes e descendentes. As cerimônias mais realizadas são o culto do fogo (jap. goma) e o culto em memória dos falecidos. O goma, que tem um complexo simbolismo, recebe outros significados como conseqüência 
de sua transplantação no Brasil. A chamada missa de goma, realizada para Fudô Myô-ô, para muitos tem o objetivo de "cortar os impedimentos espirituais", lembrando um vocabulário comum nas igrejas evangélicas. Segu ndo afirmações dos devotos, as cinzas depois da missa são utilizadas com água de diversas maneiras, como, por exemplo, con tra "encostos". Na programação anual constam ainda cerimônias mais específicas, como por exemplo o "culto da felicidade", "culto astrológico", "culto para abortos" e "culto das lanternas". O culto das lanternas é tradicionalmente realizado em memória aos antepassados, com o objetivo de que se possa viver em paz e felicidade. Outra cerimônia anual é o Hanamatsuri, que na tradição japonesa é comemorado com o nascimento do Buda, existindo um tradicional aspergimento de chá doce em uma pequena imagem do Buda menino. Ao final da cerimônia, no templo da Koyasano chá adocicado é distribuídoentre os adeptos, que trazem garrafas de plástico e consideram que o chá seja bom contra males de saúde em geral.

Adicionalmente, é possível destacar outras características sociológicas que são importantes na diferenciação desse templo do Shingon em comparação com outros templos budistas freqüentados por convertidos. A falta de uma infra-estrutura de saúde, bem como a alta taxa de desemprego e de pessoas com dificuldades financeiras, se reflete nos principais motivos das consultas em dias de semana. A sensação de insegurança e a alta taxa de criminalidade são a justificativa para a especial relevância de algumas cerimônias anuais realizadas, como o "culto con tra roubo de carros" e o "culto contra roubo de casas". Uma outra característica a ser destacada no caso do Shingon é a especialização funcional das devoções, orientadas a resultados, próximas do campo religioso brasileiro e distantes de um budismo intelectualizado. Ao lado do templo principal, por exemplo, existe uma pequena caserna dedicada ao bodisatva Jizô, na qual devotos oram e deixam bilhetes e oferendas de frutas e alimentos. ${ }^{8} \mathrm{Na}$ placa de mármore, pode-se ler em português: "Com o báculo peregrino simbolizando o domí-

\footnotetext{
${ }^{8}$ Para outro exemplo do aspecto devocional do Shingon no Brasil, consultar Clarke (1999, p. 204-205).
} 
nio sobre os elementos da natureza e a esfera traduzindo a sapiência divina, este santo preside as coisas terrenas. Além de outras inumeráveis graças esse venerável santo da terra nos proporciona a salvação dos desesperados, proteção às crianças, às lavourase o afastamento dos males que afligemo homem. Aqui registramos o agradecimento ao Sr. Kiyoshi Senzaki, que nos doou essa imagem. Erigido em 26.3.1967”.

\section{SIGNIFICADOS DO SINCRETISMO NAS PRÁTICAS DO SHINGON}

O objetivo desse item é descrever a atitude dos sacerdotes em relação ao sincretismo, bem como investigar em maior profundidade como os adeptos constroem relações e significados que servem de ponte entre diferentes sistemas religiosos. Com isso, será possível identificar algumas características teóricas, tanto da tendência acumulativa do sincretismo mágico quanto do seu papel de preencher lacunas doutrinais no desenvolvimento do budismo no Brasil.

Nas entrevistas realizadas, o aspecto mágico foi confirmadoe legitimado pelos sacerdotes do Shingon. A motivação inicial é pelo milagroso e pela solução de problemas, especialmente de saúde. Com o tempo, sem negar os aspectos milagrosos, espera-se fazer com que os adeptos entendam melhor os inúmeros significados do Shingon, aderindo mais consistentemente ao budismo. Sobre a convivência múltipla dos adeptos, ela é permitida, mas é afirmado que ela não é conveniente e que não é frutífera para o desenvolvimento espiritual. Em uma entrevista em maior profundidade, um monge afirmou buscar não utilizar o vocabulário cristão. Por exemplo, quando os freqüentadores utilizam a expressão "graças a Deus" como agradecimen to religioso nas consultas, ele reforça que tenta corrigi-los e sugere utilizar a expressão "graças aos antepassados". Ele afirma, no entanto, que os conceitos do espiritismo e das religiões afro-brasileiras são usados e facilmente entendidos pelos adeptos. Por exemplo, o termo macumba é utilizado porque, ele afirma, "macumba é o tantra africano". Da mesma forma, termos como en- 
costo e passe, freqüentemente usados no espiritismo, são utilizados ao invés dos termos japoneses que seriam semelhantes, como reishô e kaji. Ele ressalta ainda que conceito de carma, incorporado no espiritismo, é derivado das religiōes orientais e já bastante conhecido dos brasileiros. A partir dessa base, como aspecto distintivo do Shingon, surge a importância dos antepassados como causa e possibilidade de remediação do mal, além das práticas contemplativas específicas. Pessoalmente, esse monge pretende que o aspecto mais associadoao budismo seja reforçadono futuro, através da introduçãoda meditação sobre a letra A, um método particular de meditação do Shingon. Apesar dessa intenção, ele ressalta que é necessário um maior engajamento dos fiéis para essa atividade e que existe uma falta de tempo até para os inúmeros rituais que todo sacerdote do Shingon deveria realizar, além de outras atividades paralelas, necessárias para a sobrevivência financeira do monge.

Por enquanto a grande maioria dos freqüentadores e devotos tem uma dificuldade muito grande de apreender esse aspecto mais contemplativo do Shingon. Segundo uma devota que freqüenta o templo Suzano desde os anos 80 e se considera budista, o templo é um local no qual as pessoas buscam soluções para problemas de saúde, proteger negócios, contra roubos ou "limpar coisa ruim", em uma referência à macumba e a desejos negativos. Ela busca recitar o ritual do Shingon em casa, segundo suas palavras, porque no local onde ela mora tem muita macumba. Da mesma forma, ela freqüenta também a Seicho-no-ie.

Nesse sentido, muitos freqüentadores buscam no templo da Koyasan algo muito semelhan te a um centro de Umbanda, principalmente organizacionalmente e ritualmente. ${ }^{9}$ Esse é um padrão que vale para a maioria dos adeptos da Koyasan Shingon: além de uma aproximação conceitual real das religióes brasileiras e japonesas, vale lembrar que as combinações sincréticas são facilitadas pelo uso do que é combinado, dada a orientação a resultados. Como nos lembra Roger Bastide, a lógica do sincretismo da magia é acumulativo, enquanto que o sincretismo mais doutrinal tende a

\footnotetext{
${ }^{9} \mathrm{O}$ público é semelhante à clientela dos movimentos de Umbanda em São Paulo, como analisado em Negrão (1996).
} 
buscar paralelos (Bastide, 1971b, p. 154). De uma forma geral, o sincretismo de doutrinas ou mitos diferentes depende de uma teologia que propicie essa adição de diferentes elementos, através de uma relativização de conteúdos de verdade, como por exemplo a postulação da unidade das religiōes ou a Nova Era, ou mesmo a tendência mahayana de encontrar meios apropriados para se buscar a iluminação. Em contraste, um sincretismo de práticas ou mesmo de rituais parece ocorrer mais freqüen temente de maneira acumulativa. Dado que a regra básica nesse caso é sua efetividade e comprovação prática, não é incomum que se pense, em relação às práticas mágicas, que "no caso de dúvida, duas precauçôes são melhores que uma" (Bastide, 1971b, p. 160). Nesse caso, dificilmente uma síntese em forma de religião é gerada, sendo o empirismo religioso o lugar comum de fusão de elementos pertencentes a sistemas diferentes. Devido a essa tendência mágica, o sincretismo tem um caráter acumulativo, de sobreposição de práticas e conceitos, buscando aproximaçóes ao invés de realçar diferenças, em sintonia com a convivência múltipla em diversas religiōes.

Um outro aspecto do sincretismo encontrado nas entrevistas é a sua possibilidade de preencher lacunas doutrinais, ${ }^{10}$ principalmente no que se refere a tradições religiosas representadas por uma minoria, como é o caso do budismo nos países ocidentais . Essa característica é bastante presente no caso específico desse templo do Shingon. Enquanto em outros centros budistas o budismo é entendido como filosofia e o conhecimento obtido através da fonte textual é muito importante, praticamente o contrário ocorre nesse caso. Nesse sentido, parecem existir dois fatores que podem explicar o relativo desconhecimento doutrinal por parte dos adeptos. Primeiro, o claro desinteresse da maioria dos devotos por esse aspecto intelectual e mais formal, relacionado com o perfil social e a uma maior preocupação somente com os resultados práticos e imediatos que o Budismo pode trazer. Isso encontra ressonância na tendência ritualística do Shingon, exercida somen-

\footnotetext{
${ }^{10}$ Bastide também relaciona o preenchimento de lacunas com o sincretismo, mas para isso usa o conceito de memória coletiva, derivado de Maurice Halbwachs. Para maiores detalhes consultar Bastide (1971a, p. 333ff).
} 
te pelos sacerdotes. Em segundo lugar, não existem publicações que possam ser adquiridas no templo ou cursos que possam ser realizados. Existem somente alguns folhetos de descrição das práticas e do Shingon, que somente alguns devotos mais antigos possuem. Por outro lado, também é muito difícil encontrar quaisquer informações sobre o Shingon no mercado editorial em português. Devido a esses fatores, é possível sugerir que essas lacunas, reaisou devidasa desconhecimento, sejam preenchidas atravésdo sincretismo, através da semelhança e justaposição com elementos mais comuns e próximos das religiōes brasileiras ou em outros movimentos da Nova Era.

Dado esses aspectos funcionais do sincretismo, cada adepto tem uma relativa liberdade de combinação que reflete a tendência religiosa atual, o que muitas vezes inclui um elemento mágico, mas não se reduz a ele, podendo incluir também uma opção intelectual. Um dos exemplos de como isso ocorre pode ser mostrado através de uma entrevista em profundidade realizada com uma adepta que mora em São Paulo. Apesar de ser um caso particular, ele mostra essa suspensão de barreiras entre o budismo e outros sistemas religiosos, bem como as associações e justaposições possíveis no plano mais intelectual. Formada em Letras, ela já se considera budista no Shingon há muitos anos, apesar de ter freqüentado várias linhas budistas e também outras religiōes orientais. Ela buscou o Shingon a partir de um problema de saúde, tendo já lido bastante sobre religiōes orientais e revistas de tendência Nova Era. Como adepta ela reconhece e valoriza o padrão popular do Shingon em Suzano, apesar de sentir falta de um aspecto mais intelectual e de continuidade em termos de livros ou cursos doutrinais. Em contraste com outros grupos budistas, especialmente os grupos Zen, ela sente que no Shingon existe uma liberdade e uma tendência mais popular.

As religiōes afro-brasileiras têm um papel importante no seu entendimento do Shingon, onde se pode observar a suspensão de barreiras entre os dois sistemas. Ela considera o carma e o culto aos antepassados como um dos pilares tanto do budismo como das religiões africanas. Mesmo no caso da Igreja Católica seria possível praticar o culto aos antepassados através de uma missa para o sobrenome, o que ela já solicitou quando não pode ir ao templo em Suzano. Ex-militante do movimento negro no Brasil, ela inter-

Debates do NER, Porto Alegre, Ano 7, n. 9, P. 37-56, JAn./Jun. 2006 
preta os preconceitos e problemas da raça negra também a partir dessa concepção de carma. Os negros teriam muitos problemas devido às mortes na escravidão, como mortes violentas e suicídio. $\mathrm{O}$ fato dos negros também terem sido forçados a vir para o Brasil, quebrando forçadamente uma vida na África, também seria um dos motivos desse carma histórico.

Adicionalmente, ela vê muitas semelhanças entre a religiosidade africana e o Shingon, desde o culto de elementos da natureza e as devoçôes e oferendas a eles e aos antepassados, até aspectos estéticos como o uso das roupas brancas, dos mantras e dos sinos e tambores. Indo mais além, ela considera os bodisatvas como intermediários, podendo ser vistos como os santos do catolicismo ou os orixás do candomblé. No seu caso, ela faz essa identificação com o candomblé, no qual existem vários orixás, associados também a elementos da natureza, sendo cada adepto associado a um orixá. O mesmo existiria, segundo seu depoimento, no caso do Shingon, podendo ser possível dizer que se pertence a um determinado Buda, bodisatva ou guardião. Quando se pertence a um determinado Buda do Shingon, o que em Suzano se sabe através de consulta aos monges, ${ }^{11}$ busca-se conhecer melhor a sua história e o seu mantra, o que é buscado pelas pessoas que são adeptos do templo a mais tempo. Ela coloca que dos bodisatvas do Shingon, Fudô Myô-ô seria o seu, sendo também o Buda das curas, das doenças e das dores físicas. Ela associa esse seu pertencimento ao seu orixá Abaluaê no candomblé, que sofreu muito e foi rejeitado. Ele foi queimado e teve sempre que vestir uma roupa de palha, por causa das queimaduras, "tendo chegado ao estado búdico a partir do sofrimen to físico".

\section{CONCLUSÕES}

Apesar do carma ser inicialmente entendido como um elemento individualregidopor umaregra impessoalele foifreqüentementeentendido,dentro

\footnotetext{
${ }^{11}$ No Japão, ortodoxamente essa relação é definida em um ritual de iniciação mais formal, na qual o devoto lança uma flor em uma mandala do Shingon, o que não é realizado no Brasil. Para maiores detalhes da prática no Japão consultar Yamasaki (1988, p. 176).
} 
da expansão do budismo para o Extremo Oriente, como algo que poderia ser melhorado por diversas formas de se obter mérito. Historicamente esse mérito estava associado a um relacionamento de doação para com a sangha budista. Com o desenvolvimento do budismo Mahayana novas formas de obtenção de mérito surgiram. Esse mérito, entendido como um carma positivo, pode ser recebido por bodisatvas ou então doado a outros seres. No Japão esse conceito de carma e mérito foi interpretado como parte do culto aos antepassados.

No Brasil essa visão vem de encontro com o conceito de carma a partir do espiritismo, religião que se combinou com os movimentos afro-brasileiras e que é um pólo do continuum de religiōes mediúnicas e de possessão. Em termos analíticos, o budismo Shingon no Brasil é ilustrativo por mostrar o sincretismo entre a religiosidade japonesa e brasileira e ser uma faceta do continuum religioso nipo-brasileiro, que inclui movimentos xamanísticos (Mori, 1992, p. 57-76). Para o contexto dos grupos budistas populares no Brasil, é essencial destacar o carma e a influência de espíritos como fontes dos problemas a serem resolvidos. Esses elementos comuns se tornam pontos de partida para a reinterpretação de conceitos associados ao mundo cultural japonês, a partir de um sincretismo que tem tanto uma função acumulativa quanto de preenchimento de lacunas doutrinais.

\section{REFERENNCIAS}

BASTIDE, Roger. As religiōes africanas no Brasil. Contribuição a uma Sociologia da Interpenetração de Civilizações (2 vol.). São Paulo: Pioneira, 1971a [1960].

African civilizations in the New Wonld. London: Harper and Row Publishers, 1971b.

BECHERT, Heinz. Buddhism in Ceylon and studies on religious syncretism in buddhist countries. Report on a Symposium in Göttingen. Göttingen: Vandenhoeck und Ruprecht, 1978.

CAMARgO, Când ido Procó pio. Católicos, Protestantes e Espíritas. Petrópolis: Vozes, 1973.

Debates do NER, Porto Alegre, Ano 7, n. 9, P. 37-56, JAn./Jun. 2006 
CLARKE, Peter. JapaneseNew ReligiousMovements in Brazil: From ethnic to 'universal' Religions. In: CRESSWELL, Jamie; WILSON, Bryan. NewReligious Movements challenge and response. London: Routledge, 1999, p. 197-211.

GOEPPER, Roger. Das kultbild im ritus des esoterischen buddhismus Japan. Opladen: Westdeutscher Verlag, 1983.

GOMBRICH, Richard; OBEYESEKERE, Gananath. Buddhism transformed: religious change in Sri Lanka. New Jersey: Princeton University Press, 1988.

HARDACRE, Helen. Lay buddhism in contemporary Japan: Reyûka i Kyôdan. Princeton: Princeton University Press, 1984.

OSAKI,André Masao. As religiōes japonesas no Brasil. São Paulo: Loyola, 1990.

MIKIKO, Nagai. Magic and self-cultivation in a new religion: the case of Shinnyoen. In: Japanese Joumal of Religious Studies, 22/34, 1995, p. 301-320.

MORI, Koichi. Processo de "amarelamento" das tradicionais religiôes brasileiras de possessão - mundo religioso de uma Okinawana. In: Estudos Japoneses, n. 18, 1992, p. 57-76.

NEGRÃO, Lísias Nogueira. Entre a cruz e a encruzilhada: formação do campo umbandista em São Paulo. São Paulo: Edusp, 1996.

PYE, Michael.Shinto, primal religionand international identity. In: Marburg Journal of Religion, vol. 1, n. 1, 1996, <http:// www.uni-marburg.de/ religionswissenschaft/journal/mjr/Helsinki.html>, acessado em 5.8.2003.

READER, Ian; TANABE, George. Pratically religious. wordly benefits and the common religion of Japan. Honolulu: University of Hawaii Press, 1998.

SPIRO, Michael. Buddhism and society: a great tradition and its burmese vicissitudes. Berkeley; Los Angeles: University of California Press, 1982.

TEN GROTENHUIS, Elisabeth. Japanese mandalas: representations of sacred geography. Honolulu: University of Hawaii Press, 1999.

YAMASAKI, Taiko. Shingon: japanese esoteric buddhism. Boston; London: Shambala, 1988. 